\title{
ANALISIS IMPLEMENTASI SISTEM INFORMASI OKUPANSI KAMAR RAWAT INAP BERBASIS WEBSITE PADA PUSKESMAS KERANGGAN (TANGERANG SELATAN)
}

\author{
Florentina Kurniasari ${ }^{1}$, Imanuel Sudarsono ${ }^{2}$, Meidy Nurindah Hasri ${ }^{3}$, Maria Bernadeta \\ Erika Oktoviani $^{4}$, Bonaventura Kusuma Jaya ${ }^{5}$, Yoke Ranlym Arifin ${ }^{6}$, Daniel Antonius ${ }^{7}$ \\ 1,2,3,4,5,6,7 Manajemen Teknologi, Universitas Multimedia Nusantara
}

florentina@umn.ac.id, imanuel.sudarsono@student.umn.ac.id, meidy.nurindah@student.umn.ac.id, maria.bernadeta@student.umn.ac.id, bonaventura.kusuma@student.umn.ac.id, yoke.ranlym@student.umn.ac.id, daniel.antonius@student.umn.ac.id

\begin{abstract}
Abstrak
Sistem Informasi Okupansi Kamar Rawat Inap Berbasis Website pada Puskesmas Keranggan Tangerang Selatan merupakan media informasi dari Puskesmas Keranggan berupa jam operasional, ketersediaan kamar rawat inap, jenis pelayanan, dan sebagainya. Sistem informasi ini diimplementasikan dengan tujuan untuk mengatasi adanya kesulitan pengaturan ketersediaan kamar rawat inap yang masih dilakukan secara manual. Implementasi sistem informasi rawat inap ini diharapkan dapat meningkatkan kualitas pelayanan kesehatan bagi pasien yang harus rawat inap karena menyediakan data aktual terkait jumlah kamar rawat inap yang tersedia. Sehingga apabila tidak ada ketersediaan kamar, maka Puskesmas Keranggan akan dapat segera merujuk ke Puskesmas/RSUD terdekat. Sistem ini juga terintegrasi dengan sistem data SIPURA yang dimiliki oleh Puskesmas Keranggan, yang menyediakan informasi terkait jadwal tenaga kesehatan dan dokter, jadwal layanan kesehatan seperti imunisasi serta informasi lain terkait program dan kegiatan yang diselenggarakan oleh Puskesmas Keranggan. Sistem informasi dan website ini juga dan website juga menyediakan kolom interaksi dimana pengunjung website tersebut dapat mengajukan pertanyaan terkait layanan kesehatan Puskesmas Keranggan dan akan dijawab oleh petugas Puskesmas Keranggan yang ditunjuk. Pengumpulan data dilakukan baik secara primer berupa wawancara dan survei serta didukung oleh studi kepustakaan. Sedangkan untuk pembangunan software website ini sendiri menggunakan CMS Joomla.
\end{abstract}

Kata Kunci: sistem informasi, okupansi kamar rawat inap, website, CMS Joomla, puskesmas keranggan

\section{PENDAHULUAN}

Pembangunan kesehatan merupakan salah satu komponen pembangunan nasional yang dilaksanakan Pemerintah Indonesia untuk meningkatkan kesadaran, kemauan, serta kemampuan hidup masyarakat. Salah satu program yang dilaksanakan adalah Program Indonesia Sehat. Program ini melaksanakan tiga pilar utama yaitu: (1) penerapan paradigma sehat, (2) penguatan pelayanan kesehatan, (3) pelaksanaan jaminan kesehatan nasional (JKN) dengan tujuan untuk menciptakan keluarga-keluarga sehat. Keluarga menjadi fokus karena fungsi-fungsi keluarga menurut Friedman (1998) 1) fungsi afektif, 2) fungsi sosialisai, 3) fungsi reproduksi, 4) fungsi ekonomi, 5) fungsi pemeliharaan kesehatan. Dalam usaha menjangkau terwujudnya keluarga sehat, salah satu pendekatannya adalah dengan Pusat Kesehatan Masyarakat (Puskesmas). Puskesmas dapat meningkatkan jangkauan layanan kesehatan kepada

$$
\text { Teknologi Tepat Guna }
$$


keluarga-keluarga di dalam suatu wilayah. Sesuai dengan fungsi Puskesmas untuk mewujudkan masyarakat yang, 1) Memiliki perilaku sehat yang meliputi kesadaran, kemauan, dan kemampuan hidup sehat. 2) Mampu menjangkau pelayanan kesehatan bermutu. 3) Hidup dalam lingkungan sehat. 4) Memiliki derajat kesehatan yang optimal, baik individu, keluarga, kelompok dan masyarakat.

Puskesmas selain sebagai pusat pembangunan kesehatan wilayah, diharapkan dapat membina masyarakat untuk menerapkan hidup sehat, dan dapat memberikan layanan kesehatan masyarakat secara menyeluruh. Pendekatan terwujudnya keluarga sehat melalui puskesmas dilakukan dengan kegiatan-kegiatan sebagai berikut: 1) melakukan pendataan kesehatan keluarga, 2) membuat dan mengelola data puskesmas, 3) menganalisis, merumuskan intervensi masalah kesehatan, serta menyusun rencana kerja puskesmas, 4) melaksanakan penyuluhan kesehatan dengan kunjungan rumah, 5) melaksanakan pelayanan profesional, 6) melaksanakan sistem informasi dan pelaporan puskesmas. Kegiatan-kegiatan tersebut diintegrasikan dalam langkah-langkah manajemen puskersmas yang meliputi pengawasan, penggerakan dan pelaksanaan, pengawasan, pengendalian serta penilaian.

Kualitas pelayannan puskesmas tidak lepas dari peran penting para pemangku kepentingan yaitu Dinas Kesehatan Kabupaten/Kota sebagai pemilik puskesmas berperan mengembangkan sumber daya, koordinasi, pemantauan dan pengendalian agar Peratuan Menteri Kesehatan Nomor 75 Tahun 2014 dapat terpenuhi. Dinas Kesehatan Provinsi berperan memfasilitasi dan mengkoordinasikan seluruh Dinas Kesehatan Kabupaen/Kota di wilayahnya. Kementrian Kesehatan sebagai Pemerintah Pusat berperan menetapkan norma, standar, prosedur, dan kriteria dalam rangka penyelenggaraan pemerintahan, serta mengawasi dan membina pelaksanaan pemerintahan yang menjadi kewenangan daerah. Peran dan tanggung jawab lintas sektor berperan menentukan keberhasilan Program Indonesia Sehat dengan mengukur 12 Indeks Keluarga Sehat.
Puskesmas Kranggan melayani wilayah Keranggan dan Pademangan yang melayani 1766 jiwa penerima kartu sehat puskesmas, termasuk di dalamnya dengan keadaan gizi baik 191 balita, gizi buruk 3 balita, gizi kurang 7 balita, dan gizi lebih 183 balita dengan jumlah kunjungan pasien 1170 orang pengguna JPS-BK (Jaringan Pengaman Sosial Kesehatan), dan 33 orang pengguna ASKES (Asuransi Kesehatan). Puskesmas Keranggan memiliki 6 kamar rawat inap yang digunakan untuk melayani pasien dengan perawatan intensif. Pengaturan okupansi kamar tersebut masih manual, sehingga pengguaannya tidak dapat dipantau secara real time oleh petugas Puskesmas maupun calon pasien yang membutuhkan.

Pengaturan secara manual menimbulkan ketidakpastian ketersediaan kamar sehingga layanan petugas untuk calon pasien rawat inap tidak efektif, sedang di sisi calon pasien menganggap Puskesmas tidak menyediakan kamar rawat inap. Kesalahan pengertian ini dapat diatasi melalui perbaikan tampilan website Puskesmas Keranggan dengan menyampaikan informasi ketersediaan kamar rawat inap, sehingga petugas Puskesmas maupun masyarakat dapat mengetahui informasi ketersediaan kamar rawat inap secara real time. Informasi ini dapat menjadi evaluasi penggunaan Bed Occupancy Rate (BOR)sebagai indikator tinggi rendahnya pemanfaatan tempat tidur rumah sakit. Bed Occupancy Rate adalah presentase pemakaian tempat tidur pada satuan waktu tertentu. Nilai ideal BOR adalah 70-80\% menurut Depkes (2015).

Tujuan PKM ini adalah memberikan informasi real time ketersediaan kamar rawat inap di puskesmas Keranggan kepada pasien puskesmas Keranggan, pasien juga dapat melakukan registrasi online pada website yang sama. Untuk petugas medis dapat menganalisa terhadap okupansi kamar rawat inap dari pembaharuan data tsb.

Manfaat pelaksanaan PKM ini adalah memberikan kemudahan pendataan pasien calon pengguna kamar rawat inap yang mendaftar secara online oleh petugas medis, serta data yang selalu terbarukan (real time) mengenai ketersediaan kamar 
rawat inap, dan memberikan berbagai informasi melalui website.

Solusi yang dipilih untuk menangani masalah di puskesmas Keranggan adalah dengan memperbaiki tampilan website puskesmas Keranggan dan penambahan fitur pendaftaran pasien secara online dan ketersediaan kamar rawat inap. Solusi ini dipilih setelah melakukan survey dan penetapan lokasi PKM serta melakukan analisis SWOT lingkungan internal dan eksternal puskesmas Keranggan.

\section{METODE}

Metode penelitian yang digunakan dalam kegiatan pengabdian masyarakat ini adalah deskriptif dan survei untuk merumuskan permasalahan dan solusi. Lokasi yang digunakan dalam kegiatan pengabdian masyarakat yaitu Puskemas Keranggan terletak di Kecamatan Setu, Kota Tangerang, Provinsi Banten. Kegiatan pengabdian masyarakat ini dilaksanakan mulai Juli 2019 sampai Desember 2019. Metode deskriptif digunakan untuk mengetahui kondisi Kerangan yang meliputi demografi, fasilitas, dan layanan. Pada survei demografi didapatkan data jumlah penduduk yang dikelompokkan berdasarkan jenis kelamin, usia, dan agama. Keranggan memiliki jumlah penduduk 6.081 dengan 3.131 laki-laki dan 2.950 perempuan. Jumlah rumah tangga Keranggan adalah 1.476 kepala dengan rata-rata penduduk rumah tangga 4,12. Penduduk Keranggan memiliki 3 pemeluk agama dengan rincian agama Islam (5.818 orang), Kristen (42 orang) dan Katolik (19 orang) dan sisanya tidak disebutkan. Survei fasilitas pada kegiatan pengabdian masyarakat mencakup fasilitas pendidikan dan fasilitas kesehatan yang ada pada Kelurahan Keranggan.

Survei layanan pada kegiatan pengabdian masyarakat mencakup data jenis layanan imunisasi yang diberikan kepada bayi di Kelurahan keranggan. Pada program keluarga berencana, Keranggan memiliki 1 bidan dan 3 perawat dengan 500 peserta KB baru dan 1388 peserta KB aktif. Alat KB yang digunakan pun beragam mulai dari IUD (12), Implant (32), suntik (958), pil (281) dan kondom (105). Dalam kegiatan pengabdian masyarakat juga dilakukan survei pada seluruh website puskesmas Kota Tangerang Selatan untuk mengetahui kebutuhan pada setiap Puskesmas dalam interaksi antara pihak Puskesmas dan calon Pasien. Pengumpulan data primer dilakukan menggunakan teknik wawancara kepada Kepala Puskesmas Keranggan dan Staff IT untuk menmperoleh gambaran permasalahan yang dihadapi Puskesmas. Berdasarkan hasil wawancara dengan pihak Puskesmas Keranggan dapat dijelaskan bahwa permasalahan yang terjadi di Puskesmas Keranggan adalah kebutuhan informasi oleh calon terkait ketersediaan kamar rawat inap dan pendaftaran pasien secara online agar memudahkan pasien di daerah Keranggan dan Pademangan. Pembuatan sistem informasi berupa website menggunakan CMS Joomla sebagai jawaban dari permasalahan kebutuhan informasi pada Puskesmas Keranggan.

\section{HASIL DAN PEMBAHASAN}

\section{Solusi Permasalahan}

Solusi untuk menjawab permasalahan akan sulitnya pengaturan / okupansi kamar rawat inap dalah dengan menyiapkan program berupa pengaturan / okupansi kamar rawat inap yang dapat diakses oleh petugas Puskesmas dan dapat ditampilkan pada dashboard di ruang tunggu pasien.

Solusi permasalahan yang penulis dapatkan adalah hasil dari analisa SWOT (Strengths, Weakness, Opportunity, Threat) dari beberapa aspek yang dimiliki oleh puskesmas yang pembahasannya adalah sebagai berikut: 1) Kekuatan (Strengths), kekuatan dari aspek pelayanan dan sarana \& prasarana di puskesmas Keranggan sudah memiliki pelayanan rawat jalan, IGD, rawat inap, dan penunjang intensif. Oleh karena itu, kepercayaan masyarakat terhadap puskesmas ini cukup baik yang dibuktikan dengan adanya pasien yang datang dari luar Keranggan dan kunjungannya yang terus meningkat setiap tahunnya. Sedangkan dari aspek SDM, puskesmas Keranggan memiliki pemimpin yang berdedikasi tinggi yang dicerminkan dari kepercayaan masyarakat terhadap puskesmas Keranggan dan SDM medis ataupun non medis memiliki jumlah sebanyak 30 orang sehingga mampu melayani dengan maksimal. Dari aspek

$$
\text { Teknologi Tepat Guna }
$$


Keuangan, puskesmas Keranggan mendapat sumber dana dari pemerintah bersumber dari APBD dan pendapatan dari pasien umum. 2) Kelemahan (Weaknesses), kelemahan puskesmas Keranggan dari aspek pelayanan adalah beberapa pelayanan serta kompetensi SDM masih di bawah standard dan pengelolaan administrasi masih belum tersistem digital sehingga pelayanan kurang maksimal khususnya untuk pelayanan ketersediaan kamar karena jumlah kamar seringkali kurang ketika dibutuhkan. Sedangkan dari aspek keuangan, pendapatan dari hasil perolehan pelayanan masyarakat umum masih minimal.dan anggaran dari APBD yang ada masih sangat terbatas.Jika melihat dari aspek sarana dan Prasarana pun menunjukkan kelemahan di antaranya tata letak Puskesmas yang kurang kondusif baik secara layout dan keleluasaan bagi pengunjung atau pun pasien serta tempat parkir terbatas. 3) Peluang (Opportunities), puskesmas Keranggan dari aspek pelayanan dipilih sebagai puskesmas rujukan dari tiga daerah sekitarnya dan memiliki lokasi yang mudah dicapai. Sedangkan dari aspek SDM, puskesmas Keranggan memperkerjakan pegawai yang tinggalnya masih di sekitar Keranggan dan daerah Keranggan sendiri sering dijadikan sebagai desa binaan oleh perusahaan dan institusi pendidikan. Apabila dari aspek keuangan dan sarana \& prasarana, puskesmas Keranggan memiliki peluang bantuan dan dukungan dari banyak pihak. 4) Ancaman (Threats), masyarakat semakin kritis terhadap pelayanan yang ada, menginginkan adanya peningkatan pelayanan setiap waktu. SDM ahli yang terbatas menjadi ancaman bagi puskesmas Keranggan terkait pelayanan. Aspek Keuangan pun mengancam dari segi biaya yang meningkat tidak seiring dengan peningkatan dana yang diberikan oleh Pemerintah Daerah. Aspek Sarana dan Prasarana Layout dan Luasan juga yang semakin kurang memadai untuk memenuhi jumlah pengunjung dan pegawai Puskesmas yang mungkin menurunkan penilaian Puskesmas serta sistem yang mendukung untuk melayani dan meningkatkan kinerja Puskesmas yang belum dimanfaatkan secara maksimal dan menyeluruh yang tentunya dapat menurunkan penilaian Puskesmas Keranggan.
Maka dari itu, hasil analisis secara garis besar menuntut adanya perbaikan demi pelayanan puskesmas yang lebih baik agar dapat menangani pasien lebih maksimal. Pembuatan sistem secara digital seperti data yang tersedia pada dashboard yang ditampilkan untuk pengguna atau pasien tersebut bukan hanya data kamar rawat inap yang tersedia, juga dokter / bidan yang sedang bertugas, jadwal imunisasi, nomor antrian rawat jalan dan beberapa fungsi lainnya yang memudahkan pasien. Hal ini terkait efektifitas dari segi layout puskesmas yang terbatas namun pengunjung yang semakin meningkat. Riwayat dari identitas pasien yang meliputi nama, NIK, gender, usia, serta diagnosa penyakit pasien yang pernah dirawat juga akan otomatis tersimpan sebagai dokumentasi.

\section{Antarmuka Website Puskesmas Keranggan}

Website ini merupakan sebuah website profile dari Puskesmas Keranggan yang dilengkapi beberapa fitur. Website ini digunakan sebagai media perantara atau pusat informasi dari Puskesmas Keranggan, diantaranya penyampaian informasi mengenai tenaga media, jam operasional, ketersediaan kamar rawat inap, jenis pelayanan, dan sebagainya. Terdapat tiga akses pada website ini: website yang dapat diakses oleh publik, website untuk admin, dan website untuk superadmin. Gambar berikut menunjukkan bagian slider pada halaman Beranda yang menampilkan gambargambar dari Puskesmas Keranggan.

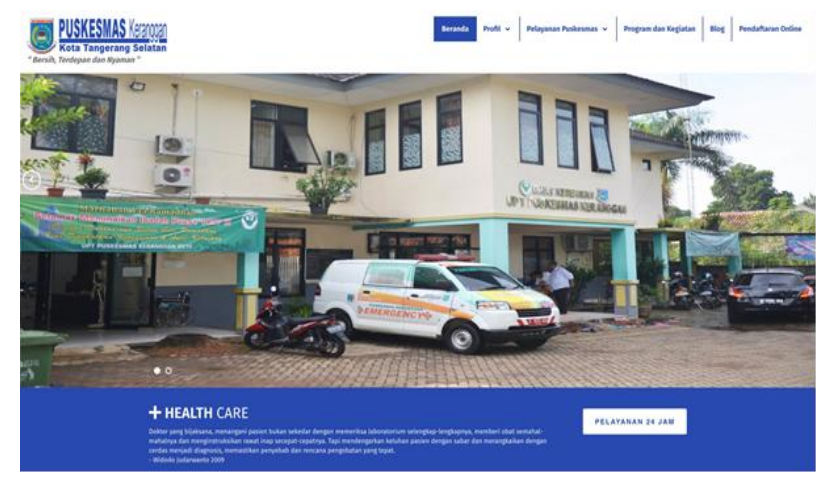

Gambar 1. Halaman Beranda (slider)

Selain perbaikan user interface website Puskesmas Keranggan, sistem operasi website Teknologi Tepat Guna 
Puskesmas Keranggan menampilkan fitur-fitur baru yaitu pendaftaran pasien secara online dan ketersediaan kamar rawat inap. Di halaman beranda menampilkan informasi mengenai Puskesmas Keranggan seperti visi dan misi, beragam pelayanan Puskesmas, pendaftaran pasien online, profil petugas medis di Puskesmas Keranggan, berita kegiatan maupun program yang diselenggarakan Puskesmas, cara menghubungi Puskesmas dan Frequently Asked Question (FAQ). Pada bagian FAQ, menunjukkan pertanyaan yang sering ditanyakan oleh pengunjung website maupun puskesmas. FAQ membantu masyarakat agar dapat dengan segera mendapatkan informasi yang diinginkan. Untuk melengkapi, ada halaman Blog yang berisikan artikel-artikel mengenai kesehatan yang dapat dibaca oleh seluruh pengunjung website.
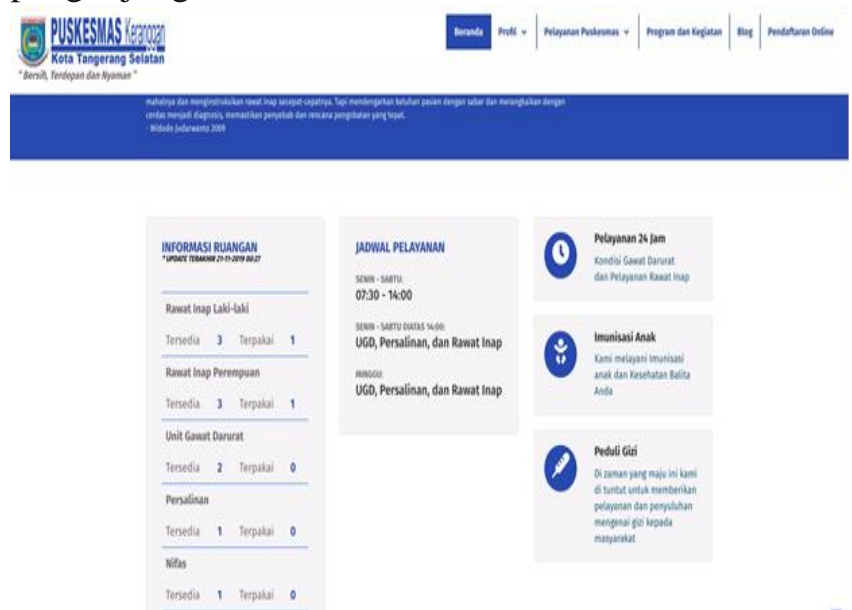

Gambar 2. Halaman Beranda (informasi ruangan, jam buka, dan pelayanan)
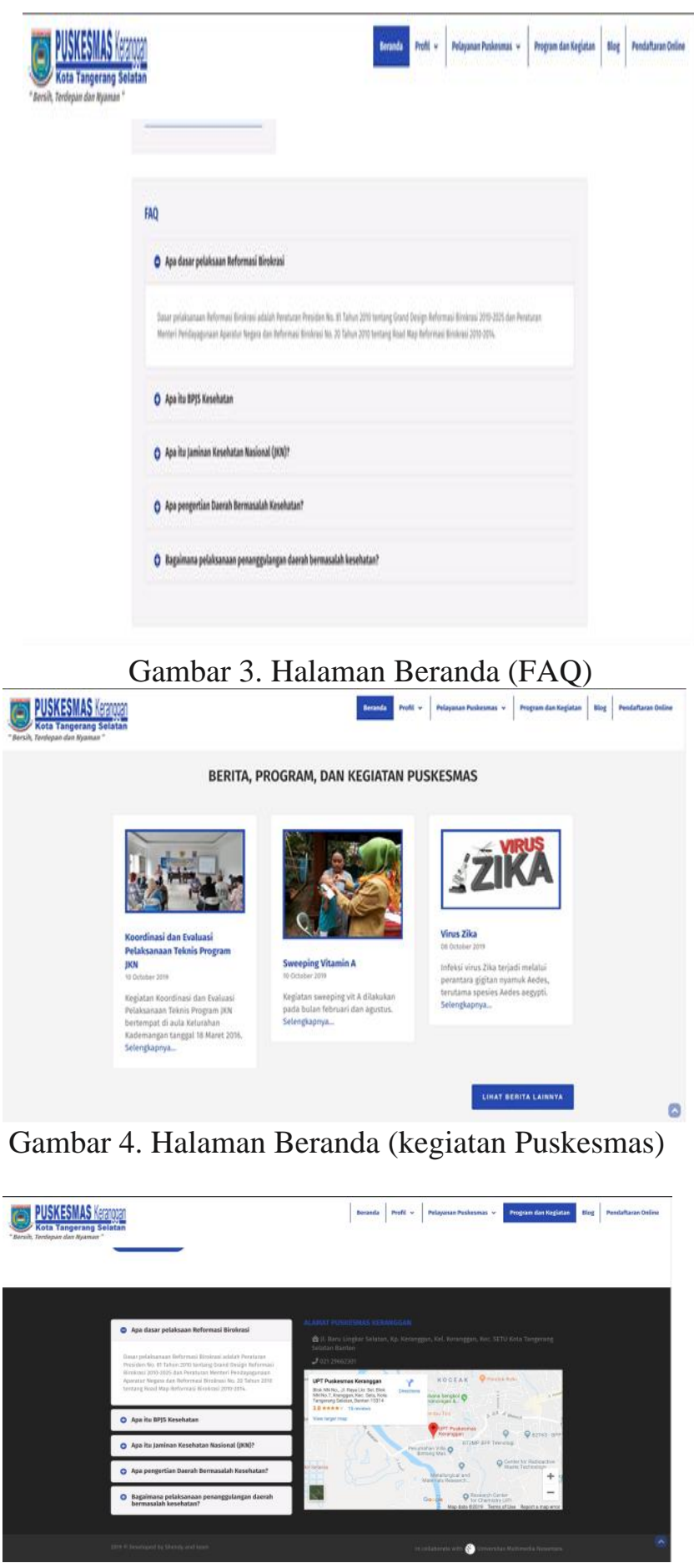

Gambar 5. Halaman Beranda (footer)

Terdapat juga tampilan visual dalam bentuk slide berupa foto-foto dari Puskesmas Keranggan.

Teknologi Tepat Guna 
Beberapa informasi yang dapat menjadi sorotan yaitu pelayanan 24 jam, jadwal buka Puskesmas, pelayanan imunisasi anak dan penyuluhan mengenai gizi kepada masyarakat. Pelayanan lainnya diantaranya Poli Gigi, Apotek, Pengobatan Umum, laboratorium, pelayanan UGD, dan lain-lain. Pada bagian informasi ruangan, menampilkan masingmasing ketersediaan ruangan diantaranya rawat inap laki-laki, rawat inap perempuan, UGD, Persalinan, dan Nifas. Apa yang ditampilkan pada dashboard, diharapkan menjadi perwakilan yang terjadi di lapangan.

\section{Antarmuka Website Admin}

Sebelum masuk ke halaman Dashboard, pengguna harus login terlebih dahulu. Setelah berhasil login, halaman Dashboard akan ditampilkan beserta menu yang dapat diakses oleh seorang Admin. Admin merupakan tenaga medis yang dapat mengubah jumlah ketersediaan kamar dan melihat list dari pasien yang mendaftar secara online. Admin dapat memperbaharui ketersediaan kamar-kamar yang tersedia. Pasien yang telah mendaftar online akan dapat dilihat informasinya oleh admin pada halaman Menu Pasien Online.

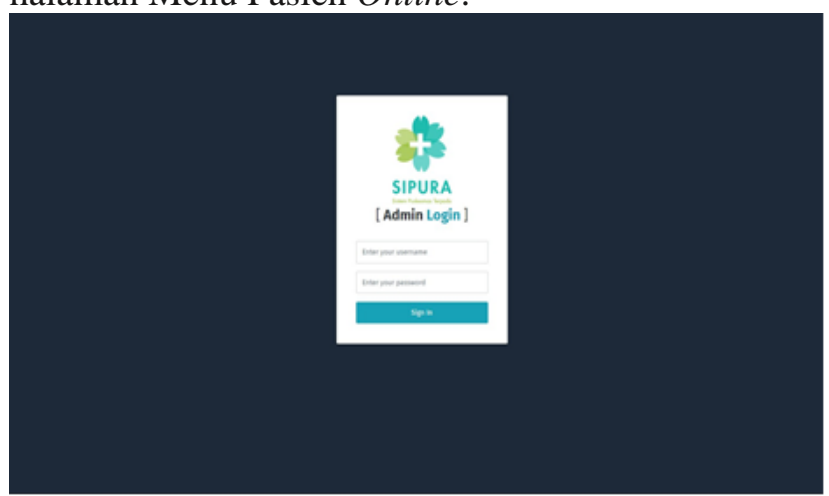

Gambar 6. Halaman Login
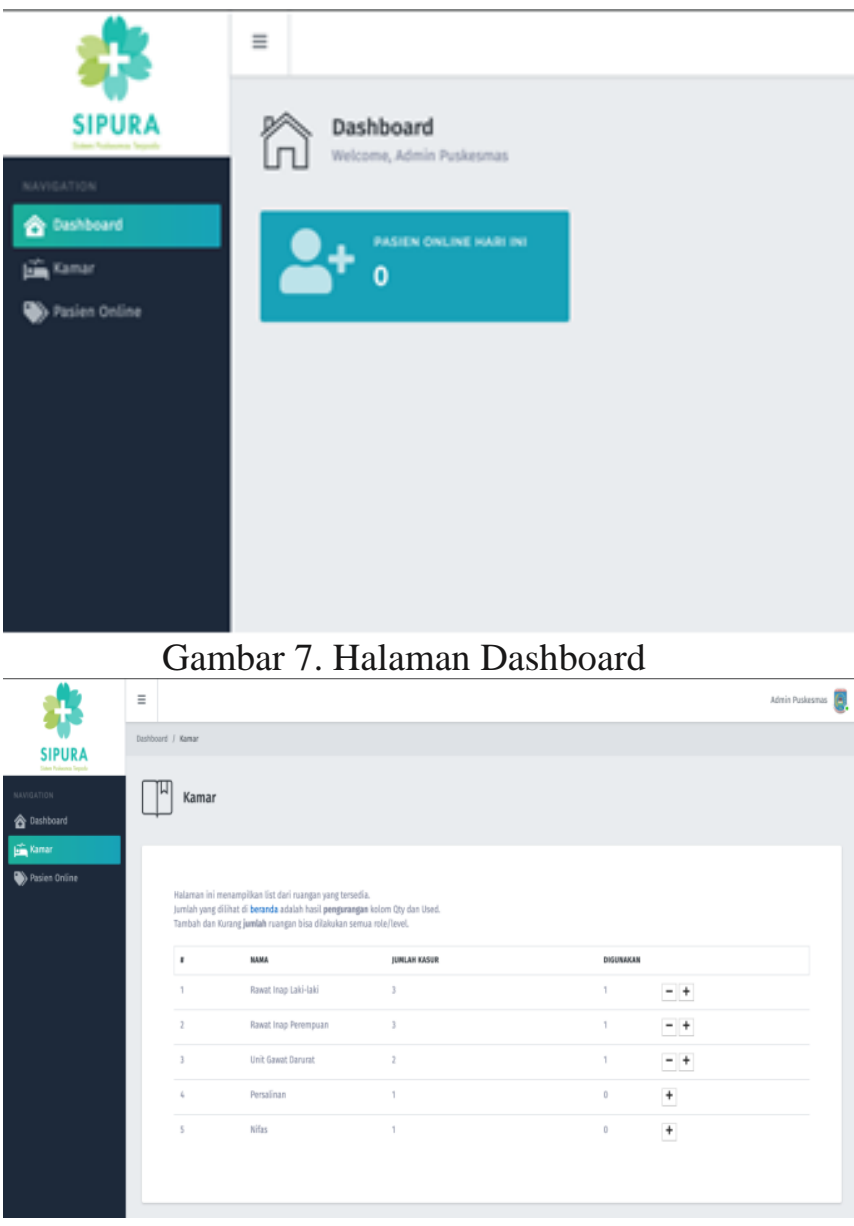

Gambar 8. Halaman Menu Kamar

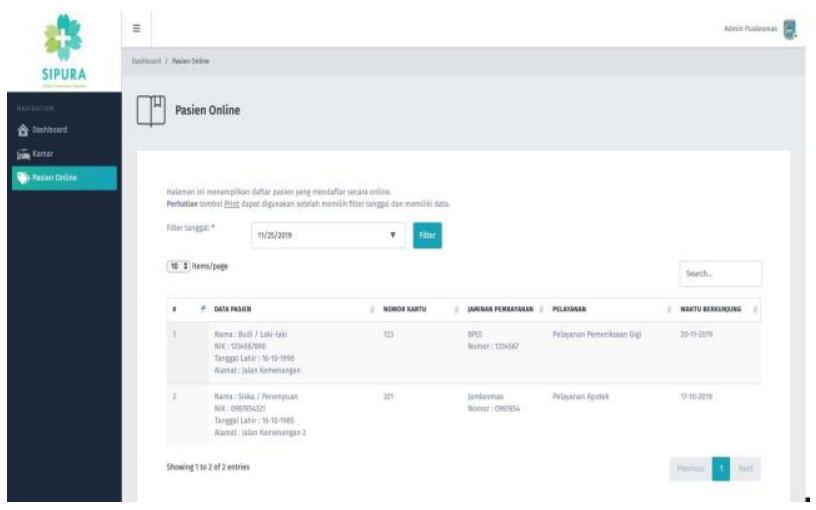

Gambar 9. Halaman Menu Pasien Online

\section{Antarmuka Website Superadmin}

Antar muka website super admin terdiri dari beberapa bagian, 1) Halaman Dashboard, sama Teknologi Tepat Guna 
seperti admin, super admin dapat masuk ke dalam sistem apabila sudah melakukan login terlebih dahulu. Setelah berhasil, akan ditampilkan halaman Dashboard dengan menu-nemu yang lebih beragam. 2) Halaman Menu Master Data- Role, menu ini digunakan superadmin untuk melakukan pengubahan master data role, user, dan blog category. 3) Halaman Menu Site Content, berisikan layout dan konten dari keseluruhan website yang dapat diubah oleh superadmin. 4) Halaman Menu Blog, digunakan superadmin untuk mengubah konten dari blog atau artikel yang akan ditampilkan pada website. 5) Halaman Menu Pelayanan, menu ini digunakan superadmin untuk mengubah jenis-jenis pelayanan yang tersedia di Puskesmas Keranggan. 6) Halaman Menu Jaminan Pembayaran, digunakan superadmin untuk mengubah atau menghapus berbagai macam jaminan pembayaran yang diperbolehkan di Puskesmas Keranggan.

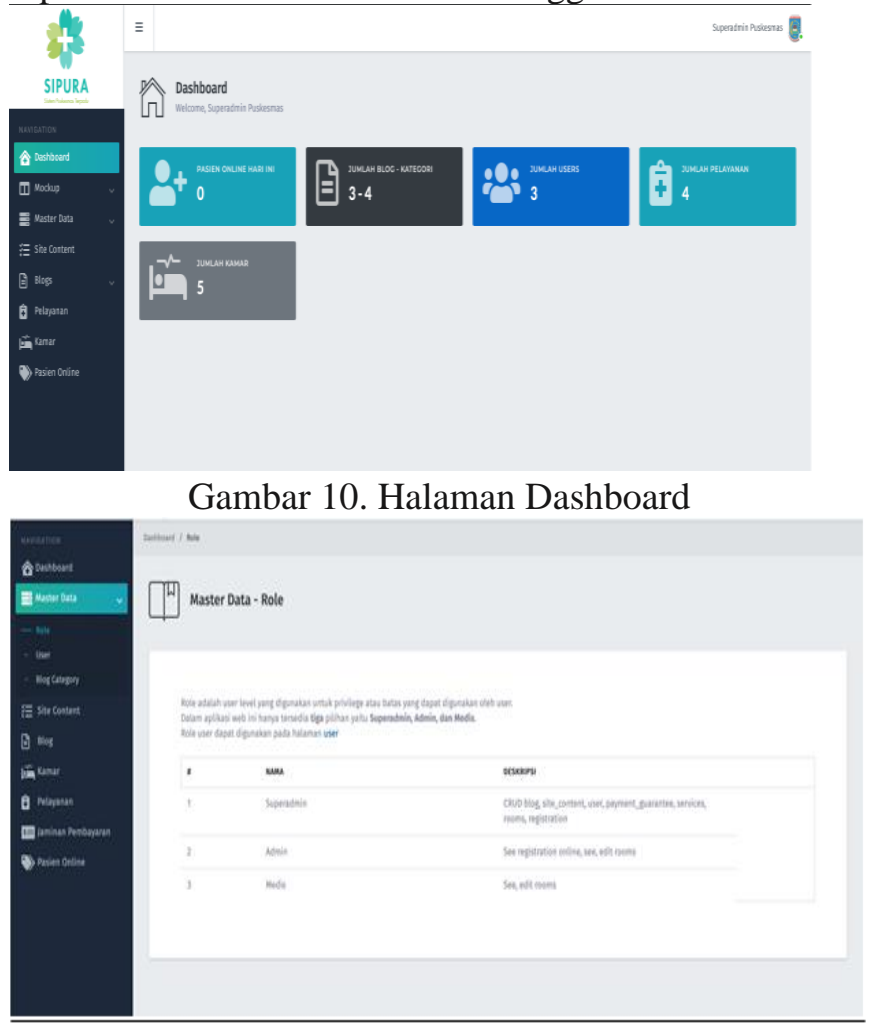

Gambar 11. Halaman Menu Master Data - Role

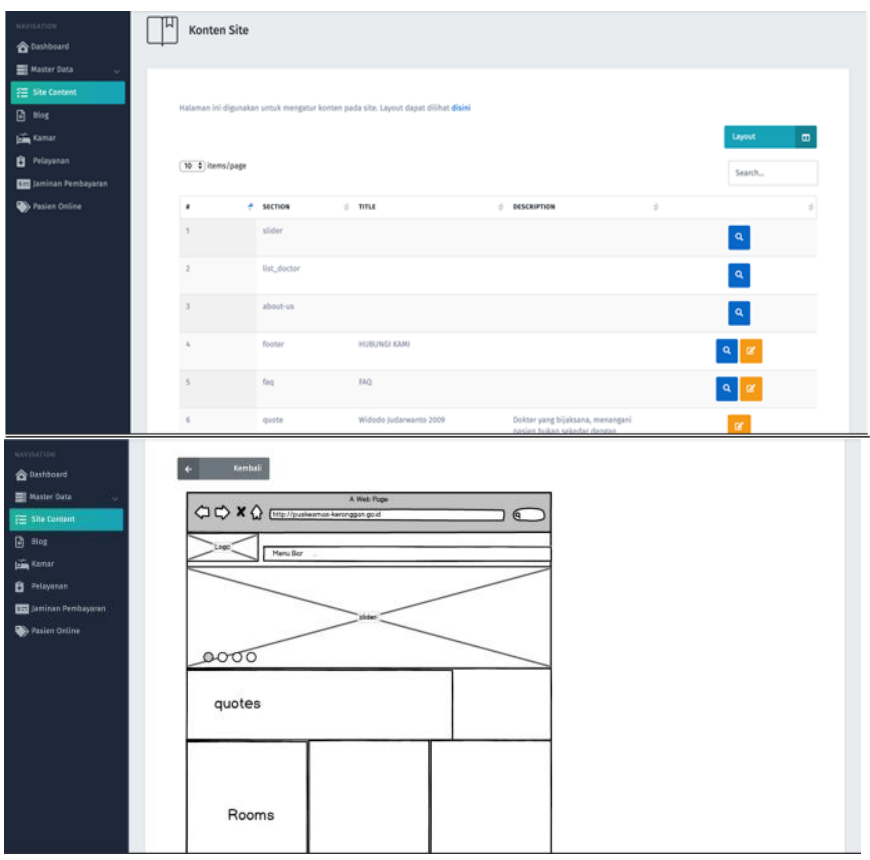

Gambar 12. Halaman Menu Site Content

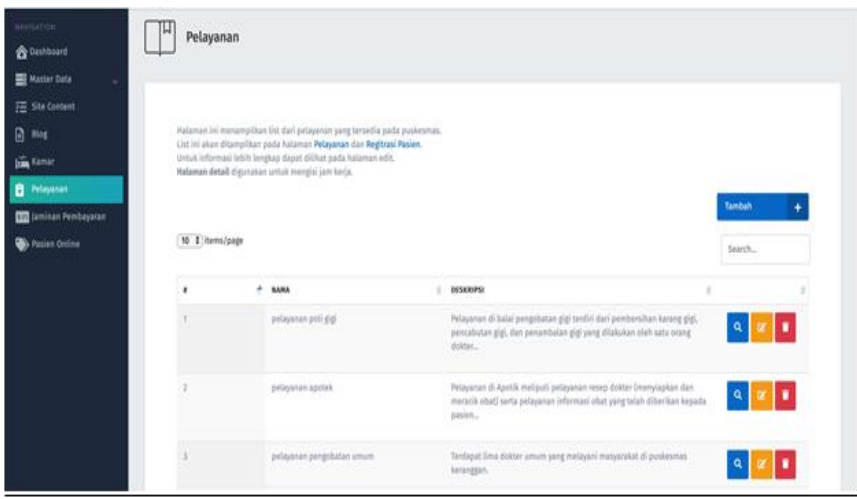

Gambar 13. Halaman Menu Pelayanan

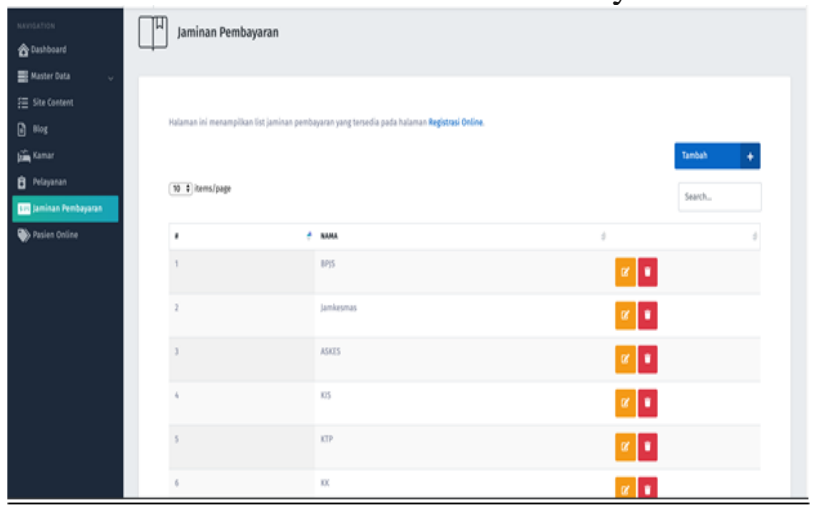

Gambar 14. Halaman Menu Jaminan Pembayaran 


\section{Hasil dan Luaran}

Dari hasil pelaksanaan program Pengabdian kepada Masyarakat (PKM) yang telah peneliti lakukan, maka telah peroleh capaian luaran sebagaimana yang disajikan pada Tabel 1 berikut:

Tabel 1

\begin{tabular}{|r|l|l|l|}
\hline No & Jenis Luaran & $\begin{array}{l}\text { Indikator } \\
\text { Capaian }\end{array}$ & $\begin{array}{l}\text { Realisasi } \\
\text { Capaian }\end{array}$ \\
\hline 1 & $\begin{array}{l}\text { Publikasi } \\
\text { ilmiah pada } \\
\text { Jurnal Buku } \\
\text { ber ISBN }\end{array}$ & Published & $\begin{array}{l}\text { 1 publikasi } \\
\text { ilmiah } \\
\text { berupa buku / } \\
\text { monograf }\end{array}$ \\
\hline $\begin{array}{l}\text { Antarmuka }- \\
\text { Website } \\
\text { Puskesmas } \\
\text { Keranggan }\end{array}$ & Terdaftar & Sertifikat HKI \\
HKI \\
$\begin{array}{l}\text { Program } \\
\text { Website } \\
\text { SIPURA }\end{array}$
\end{tabular}

ISBN (International Standard Book Number) merupakan kode untuk mengidentifikasi buku yang bersifat unik. Kode tersebut memberikan informasi tentang judul, penerbit, dan kelompok penerbit. ISBN digambarkan dengan kode yang terdiri dari deretan angka 13 digit, sebagai identifikasi pada satu judul buku yang diterbitkan oleh penerbit. Oleh karena itu penelitian mengenai desa Keranggan ini sudah terpublikasi ilmiah di ISBN yang sudah teridentifikasi dan diakui. Sedangkan hak kekayaan intelektual, atau yang disingkat HKI atau akronim HaKI, merupakan padanan kata yang biasa digunakan untuk Intellectual Property Rights (IPR), yaitu hak yang timbul dari hasil pemikiran yang menghasilkan suatu produk atau proses yang berguna untuk manusia. Pada intinya HKI adalah hak untuk menikmati secara ekonomis hasil dari suatu kreativitas intelektual. Begitu juga Website desa Keranggan yang merupakan objek dan sudah diatur dalam HKI sebagai hasil karya yang timbul dari kemampuan intelektual kami sebagai peneliti.

\section{KESIMPULAN}

Pelaksanaan pengabdian masyarakat yang dilaksanakan di Puskesmas Keranggan Tangerang Selatan menyajikan penerapan Sistem Informasi Okupansi Kamar Rawat Inap Berbasis Website. Melalui penerapan sistem informasi berbasis website ini memberikan manfaat baik bagi Puskesmas maupun masyarakat yang akan menggunakan fasilitas kesehatan di Puskesmas tersebut.

Website Puskesmas Keranggan disajikan melalui pembaharuan tampilan yang user friendly dan menampilkan menu utama yang memberikan informasi ketersediaan kamar rawat inap serta registrasi pasien secara online, hal ini memudahkan pihak Puskesmas dalam memperbarui data secara real time dan pemberian informasi yang lengkap melalui website, di sisi lain masyarakat bisa mengakses website untuk mengetahui segala fasilitas yang tersedia di Puskesmas dan mengetahui kegiatan atau program yang dilaksanakan oleh Puskesmas.

\section{SARAN}

Dari hasil pelaksanaan program Pengabdian kepada Masyarakat (PKM) yang telah dilaksanakan, terdapat beberapa saran yang dapat diberikan diantaranya adalah, 1) Website Puskesmas Keranggan dapat menjadi percontohan bagi Puskesmas lainnya di Kota Tangerang Selatan, sebagai pelayanan yang lebih banyak dijangkau oleh masyarakat karena unit pelayanan puskesmas merupakan pintu gerbang atau saringan pertama dari keluhan masyarakat dibandingkan rumah sakit, tentu puskesmas harus memberikan pelayanan yang sangat baik bersifat pelayanan kesehatan secara menyeluruh atau comprehensive health care service, yang meliputi aspek promotif, preventif, kuratif dan rehabilitative bagi masyarakat yang membutuhkan pertolongan kesehatan. Maka dari itu, penting untuk menjadi contoh yang baik agar puskesmas lainnya di Kota Tangerang Selatan atau sekitarnya bisa memberikan pelayanan yang sebaik mungkin karena adanya puskesmas ini seharusnya tersebar di setiap

$$
\text { Teknologi Tepat Guna }
$$


wilayah agar mudah dijangkau oleh setiap masyarakat untuk ditangani hingga sembuh atau perujukan untuk penanganan lebih lanjut ke rumah sakit.

2) Pengembangan website dapat dilakukan secara terus menerus dengan menyesuaikan kebutuhan Puskesmas maupun Pasien. Pengembangan teknologi dapat dilakukan mengikuti kebutuhan puskesmas, maka dari itu perlu memiliki atau berhubungan baik dengan vendor sehingga dapat terjalin komunikasi yang baik setiap terdapat kebutuhan untuk pengembangan website 3) Adanya integrasi website antar Puskesmas di Kota Tangerang Selatan untuk lebih meningkatkan pelayanan kesehatan bagi masyarakat. Hal ini terkait dengan kebutuhan puskesmas di setiap wilayah di mana puskesmas itu merupakan gerbang pertama bagi yang membutuhkan pertongan kesehatan. Sehingga adanya integrasi webiste antar Puskesmas di Kota Tangerang Selatan bisa menjadi preferensi dan menjawab kebutuhan akan data yang selalu terbarukan (real time) mengenai ketersediaan kamar rawat inap, dan memberikan berbagai informasi agar pasien bisa mendapatkan pelayanan yang efektif di puskesmas manapun yang dapat dijangkau. Sehingga tidak menjadi beban setiap pasien apabila dalam keadaan urgensi harus mendatangi puskesmas di Keranggan saja untuk mengatahui informasi pasti karena ada data real time. Hal ini bisa menjadi kesempatan oleh para pasien untuk mendatangi puskesmas mana punyang paling dekat dengan tempat ia tinggal.

\section{UCAPAN TERIMAKASIH}

Kami mengucapkan terima kasih bagi semua pihak yang telah banyak membantu dan memberikan kontribusi bagi terlaksananya kegiatan pengabdian masyarakat ini boleh berjalan dengan baik, terutama kepada Universitas Multimedia Nusantara yang telah memberikan dukungan dana dalam pembuatan website ini.

Terima kasih kepada Bapak Agus Muhdi, S.Ag selaku Lurah Keranggan dan dr. Suherman selaku Kepala Puskesmas atas kontribusi dan kerjasama dalam pelaksanaan pengabdian masyarakat yang dilaksanakan di Puskesmas Keranggan dan semua pihak yang telah ikut membantu dalam penyelesaian materi ini.

\section{REFERENSI}

Kementerian Kesehatan. 1994. Rencana pembangunan Kesehatan Menuju Indonesia sehat tahun 2010. Jakarta: Sekretariat Negara

Kementerian Kesehatan. 2016. Keputusan Menteri Kesehatan Republik Indonesia No HK.02.02/MENKES/281/2016 tentang Tim Survei Indikator Kesehatan Nasional Tahun 2016. Jakarta : Sekretariat Negara

Kementerian Kesehatan. 2019. Peraturan Menteri Kesehatan Republik Indonesia Nomor 31 Tahun 2019 tentang Sistem Informasi Puskesmas. Jakarta : Sekretariat Negara.

Kementerian Kesehatan. 2019. Indeks Pembangunan Kesehatan Masyarakat 2018. Jakarta : Badan Penelitian dan Pengembangan Kesehatan.

Pemerintah Indonesia. 2007. UndangUndang Republik Indonesia Nomor 17 Tahun 2007 tentang Rencana Pembangunan Jangka Panjang Nasional (RPJPN) Tahun 2005 - 2025. Jakarta : Sekretariat Negara

Pemerintah Tangerang Selatan. 2018. Kecamatan Setu Dalam Angka 2018.Tangerang Selatan : Badan Pusat Statistik Kota Tangerang Selatan

https://pusdatin.kemkes.go.id/article/view/1 7091900001/hasil-pendataan-keluarga-sehatdalamaplikasi-keluarga-sehat.html 